\title{
Analysis of Sorghum Stalks and Fibres for Use in the Production of Low-Cost Housing Materials
}

\author{
Taghried Abdel-Magid $^{1}\left[\right.$ Dete Walker ${ }^{1} \cdot$ Kevin Paine $^{1} \cdot$ Stephen Allen ${ }^{1}$
}

Received: 31 May 2021 / Revised: 30 August 2021 / Accepted: 2 September 2021 / Published online: 9 October 2021

(c) The Author(s) 2021

\begin{abstract}
Research into low-cost housing solutions, especially for low- and middle-income countries, has grown in recent years. Greater use of natural materials, both mineral and bio-based, offers opportunities for more affordable and sustainable materials and products. In the low- and middle-income countries, residential buildings are too expensive for most people due to the use of the concrete in buildings. Utilisation of agricultural wastes can serve a threefold purpose: (i) minimise the impact of construction products on the environment, (ii) reduce waste, and (iii) decrease the cost. The aim of this study was to investigate fibres and stalks from the sorghum plant as potential additives in low-cost brick production. Analysis of the sorghum fibres and stalks has included microstructural examination using a scanning electron microscope and mercury intrusion porosimetry, together with tensile strength testing of fibres. Fibres and stalks did not undergo chemical pre-treatment. Sorghum stalks and fibres were found to have comparable tensile strength to fibres currently used for brick production, and the methods used to prepare stalks were not found to adversely affect their strengths. Consequently, this research has shown that fibres produced from local agricultural wastes have potential for use in low-cost housing such as one-storey residential load-bearing structures and buildings.
\end{abstract}

Keywords Sorghum stalk fibres · Tensile strength $\cdot$ Scanning electron microscopy $\cdot$ Mercury intrusion porosimetry

\section{Introduction}

Synthetic and natural fibres are widely used in composite construction products to enhance their mechanical and other physical properties (Farhan et al., 2021; Q. Li et al., 2021). Natural fibres derived as co-products from food crops can offer low-cost solutions for a variety of applications (Kumar et al., 2019; Onuaguluchi \& Banthia, 2016). Sorghum is one of the top five cereal crops cultivated worldwide, and especially in Africa (Surpam et al., 2019); fibres derived from the waste plant stalks offer potential for use in construction materials. Sorghum stalks contain fibres that can be readily extracted by peeling off the inner layer of the stalk, although these fibres

This article is part of the Topical Collection on Natural Fibers: Materials of the Future

Taghried Abdel-Magid

tag.imam@gmail.com

1 BRE Centre for Innovative Construction Materials, Department of Architecture and Civil Engineering, Faculty of Engineering \& Design, University of Bath, Bath, UK are relatively short, as they are interrupted by the internodes along the stalk; this is similar to other natural plants that grow longer than $2 \mathrm{~m}$ (Chen, 2020; Perrier et al., 2017).

From the top 20 countries in the world in crop production based on crop per capita, only seven are classified in 2021 as high-income countries, while the rest are upper-middle or lower-middle income countries (FAO, 2019; The World Bank, 2021). Furthermore, according to the 2015 report prepared by DESA, "more than half of global population growth between now and 2050 is expected to occur in Africa" (UN, 2015). More affordable and sustainable forms of construction, for example, utilising agricultural wastes, are required to meet the demand for housing. Using wastes in construction can serve to both minimise the cost of housing and decrease the depletion of natural resources. The performance of bricks can potentially be improved by the inclusion of agricultural waste fibres.

Using wastes to produce useful materials can be referred to as upcycling or industrial symbiosis. Although upcycling can also refer to the reprocessing of used materials while increasing their value or quality, it can also refer to waste materials, with upcycling being the enhancement of the value or quality of these waste materials in new products, 
which contributes to the circular economy concept as an alternative to the linear economy (Sung, 2015; Sung et al., 2019). Industrial symbiosis emerges from, and applies the principles of, industrial ecology, where it benefits from interindustrial collaboration to minimise the material, energy, resources, and knowledge waste, hence, reducing waste and arising to a more sustainable approach in comparison to traditional individual sector industry (Mirata \& Emtairah, 2005). To put this in action in the construction industry, some researchers have suggested implementing an industrial symbiosis between the construction and landscape industries due to their mutual interaction with the built environment (Shooshtarian \& Hosseini, 2021). In this sense, wastes from both sectors can be utilised in the other, such as what this study is proposing.

The properties of natural fibres, straws, and stalks have been widely studied. The tensile strengths of these materials have been reported to vary significantly, from around $200 \mathrm{MPa}$ in sugarcane bagasse, sorghum rind, and kenaf fibres (Bakeer et al., 2013; Kumar et al., 2019) up to 700, 800 to $1600 \mathrm{MPa}$ in sisal, hemp and jute, and flax (Cigasova et al., 2013; Duval et al., 2011; Kumar et al., 2019; Stevulova et al., 2014; Stevulova \& Junak, 2012), respectively. However, although the tensile strength of individual fibres is one of its most important properties, it is not the only important factor influencing their use within a construction material. Other important factors include fibre and stalk bond with the surrounding matrix, essential for stress transfer, which is affected by the surface texture and morphology of the fibre and stalk particles. Improved bond can increase the fracture energy of a matrix (Ali et al., 2013; Merta \& Tschegg, 2013). The porosity of the natural fibres and stalks is another important factor, as it affects the water available for cement hydration in concrete blocks, and may affect the linear shrinkage in earth bricks, and hence, durability (Eliche-Quesada et al., 2011; Thomas, 2018). These factors, along with other social and economic considerations, can limit the wider use of natural fibres, which is often the case with construction and demolition wastes. A review by Shooshtarian et al. (2020) indicated that although the use of recycled products in construction can significantly reduce greenhouse gas emissions, they are still hindered due a number of reasons including lack of confidence and information; low expectations; cost concerns; unsupportive regulations; and limited technologies for waste recovery (Shooshtarian et al., 2020). All of these factors can apply to the case of using agricultural wastes in construction.

Agricultural wastes, such as fibres and stalks from different plants, have been utilised in several construction materials, such as mud bricks, stabilised bricks, and concrete bricks. Due to their relatively low strength in comparison to their synthetic counterparts, such as steel and glass fibres, their use in their natural state is limited. Chemical and mechanical treatment of natural plant-derived materials to improve their properties has been suggested by several researchers (Ismojo et al., 2019; Symington et al., 2009). However, even without treatment, many natural stalks and fibres satisfy the minimum requirements for low-cost construction materials, in particular earth and stabilised soil bricks, which require a compressive strength that ranges between 1.0 and 2.5 MPa (Adam, 2001; Millogo et al., 2014; Salih et al., 2020b).

To date, there has been little research into potential uses of sorghum stalk fibres. In an attempt to fill this gap, the research study presented in this paper considers the use of sorghum stalks and fibres in the production of construction materials for the purpose of low-cost housing in low- and middle-income countries. The specific aim of the study presented here has been to assess the viability of using sorghum stalk waste for use in the production of low-cost materials such as earth and cement-based matrices to be used in Sudan. Objectives of the study were to (1) identify the morphology and geometry of sorghum fibres and sorghum stalks, (2) determine the tensile strength of sorghum fibres and stalks, (3) determine the effect of change in test rate on the fibres and stalks strength, and (4) examine the effect of shredding and cutting the stalks on their strength.

\section{Materials and Methods}

For the purpose of the study, tests to identify geometry, morphology, and strength were applied on sorghum stalks and fibres. The tests conducted were mercury inclusion porosimetry, scanning electron microscopy, and tensile strength tests. As this research was focussed on low-cost housing in the country of Sudan, sorghum, one of the most cultivated crops in the country, was selected for investigation. Sorghum is the number one cereal consumed in Sudan and its waste currently has no added value. According to Sudan Trade Point (Alamin, 2007), about one-fifth of Sudan sorghum is cultivated in the eastern region. The sorghum stalks used in this study were imported from Al-Gadarif state in east Sudan. To extract the fibres, the stalks were initially submerged in water for 2 weeks. The procedure often referred to in literature as water retting (Akubueze et al., 2019; Wolela, 2019) which facilitates extraction of the fibres from the inside of the stalks when their outer parts decomposes. As can be seen from Fig. 1a, the sorghum stalks consisted of three key parts: the rind; the internal vascular bundles; and the pith. The fibres extracted for this study were targeted mainly from the inside wall of the rind, as shown in Fig. 1b. The fibres in the internal vascular bundles were also used in the study when it was possible to extract them from the pith without breakage. 
Fig. 1 S Sorghum stalks' (a) cross-sectional view and (b) fibres in the rind's inside wall

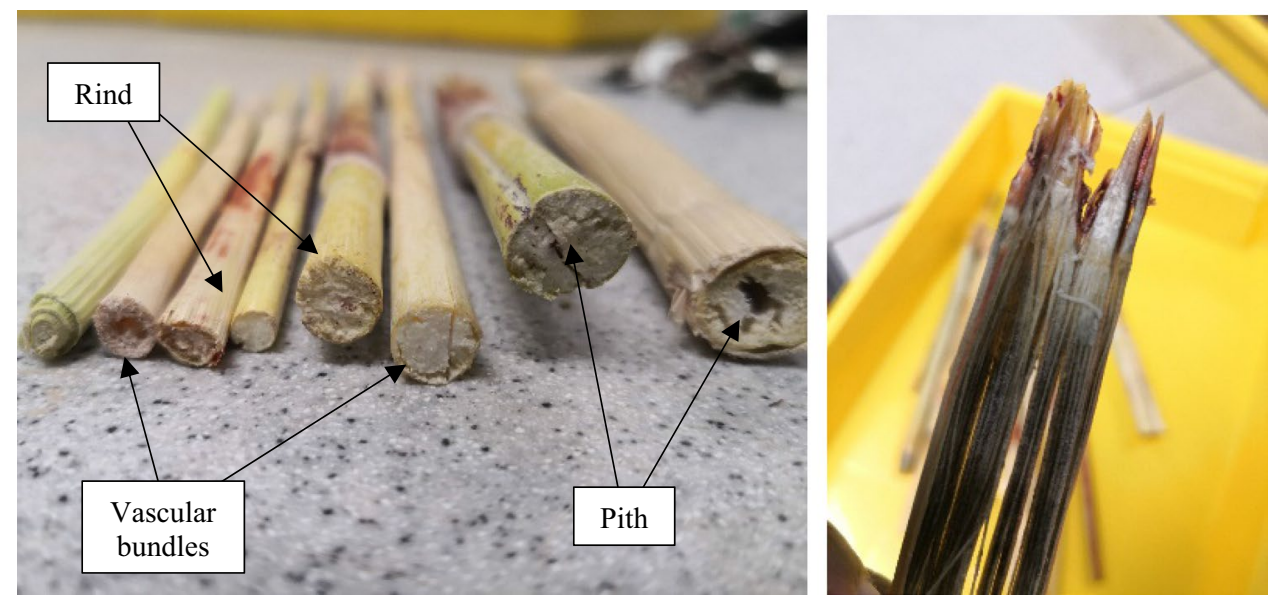

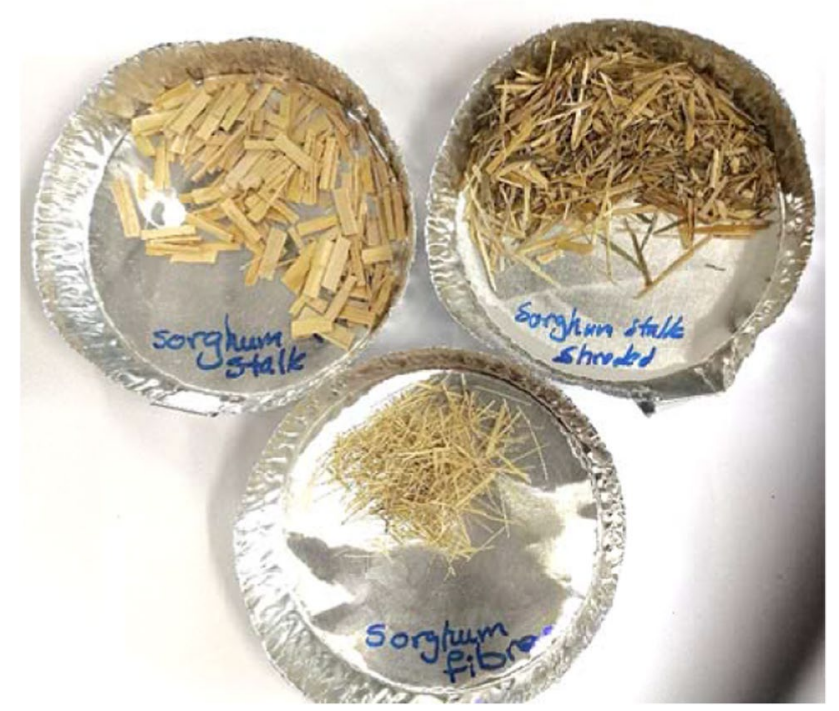

Fig. 2 Materials used: cut sorghum stalks to the top left, shredded stalks to the top right, sorghum fibres to the bottom
In addition to the fibres, the remaining sorghum stalks were also examined, for comparison, following two separate processes: (i) manually cut stalk after fibre extraction; (ii) after shredding with a blender. These are shown in Fig. 2.

Water absorbency was determined following submersion of the stalks in water for $24 \mathrm{~h}$. Specimen mass was recorded before $\left(m_{1}\right)$ and after $\left(m_{2}\right)$ immersion. The latter value was measured in a saturated dry surface condition, which was achieved by removing excess water with a paper towel. Water absorption capacity (w) was measured as follows:

$w=\frac{m_{2}-m_{1}}{m_{1}} \times 100 \%$

Pre-treatment of the fibres comprised submerging in water for 1 day after extraction, followed by surface cleaning of natural contaminants, such as wax as shown in Figs. 3 and 4 , by gentle brushing. The influence of these contaminants on the fibre tensile strength was evaluated by comparing the tensile strength of fibres both with and without contaminants.
Fig. 3 Optical microscope imaging for contaminants on fibres' surface (a) wax and (b) black spots
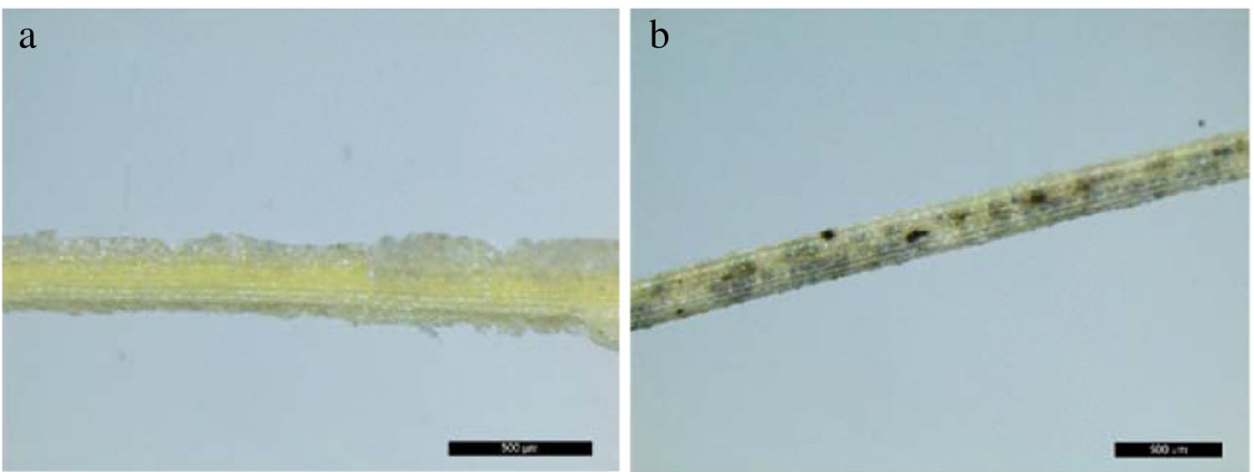


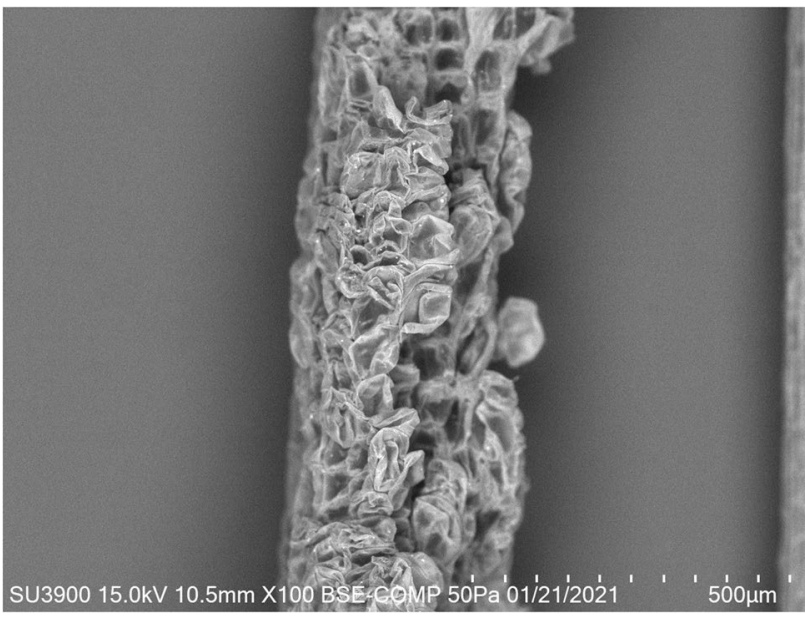

Fig. 4 SEM image of a single sorghum fibre showing wax on its surface

\section{Geometry and Morphology of Sorghum Stalks and Fibres}

For the purpose of this study, cut and shredded sorghum stalks were assumed to have a rectangular crosssection, while the sorghum fibres were assumed to be of circular cross-section. The dimensions of cut and shredded stalks were measured using a calliper, and assuming their cross-section were approximately rectangular. The fibre diameters along with the length of the internodes were measured using an optical microscope; a minimum of ten measurements were taken and the average calculated. Fibre cross-sectional areas were assumed to be solid for the purpose of calculating the tensile strength.

The pore size distribution of both the fibres and stalks was determined using mercury inclusion porosimetry (MIP). Three specimens of each were tested; the results presented here are the mean values. Samples were stored under $50^{\circ} \mathrm{C}$ for a minimum of 2 days, then were tested at a surface tension of $0.48 \mathrm{~N} / \mathrm{m}$, mercury contact angle of $140^{\circ}$, and a maximum pressure of $400 \mathrm{MPa}$. Furthermore, fibre and stalk morphology was examined under a scanning electron microscope (JEOL JSM-6480LV SEM).

\section{Tensile Strength}

Tensile stress testing was performed on a fibre gauge length of $20 \mathrm{~mm}$, at room temperature. Fibres and stalks were initially glued by their ends to a piece of paper to facilitate preparation for testing; the sides of the paper were cut once the specimen had been mounted in the universal testing

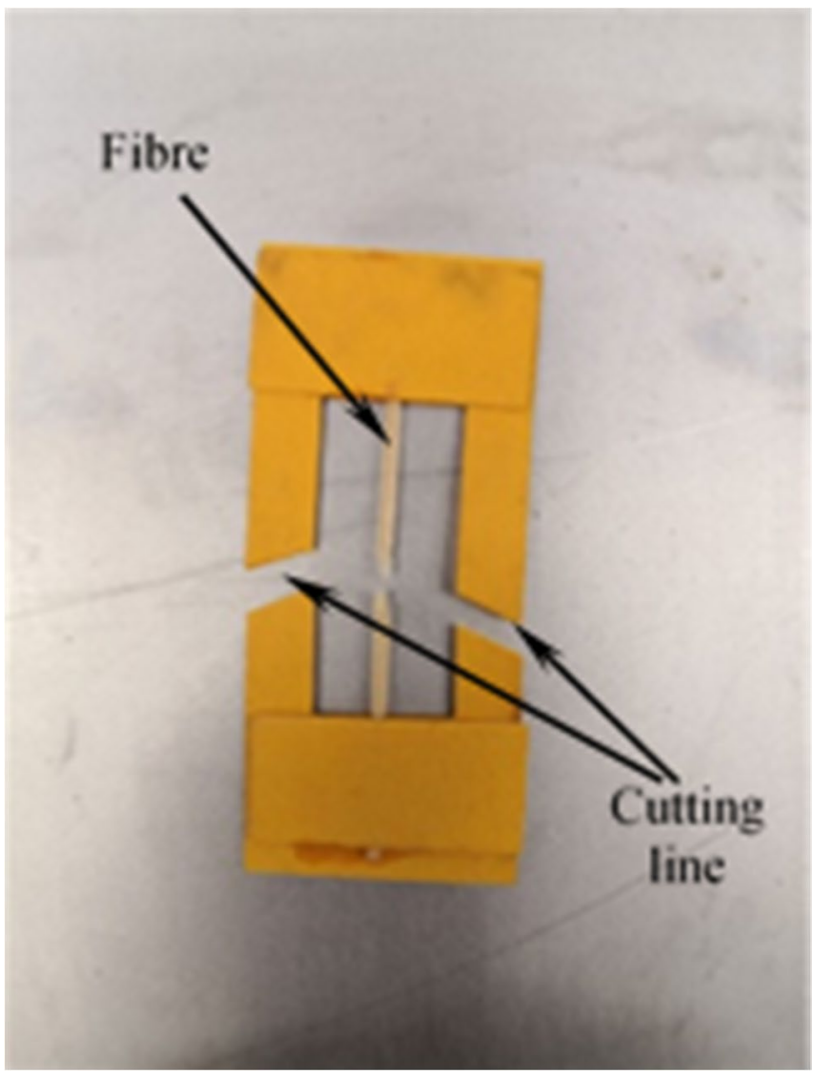

Fig. 5 Tensile test specimen

machine (Instron 3369 test frame), but prior to force application, as shown in Fig. 5. A total of 66 individual sorghum fibres were tested at a rate of $0.5 \mathrm{~mm} / \mathrm{min}$ (strain rate $2.5 \mathrm{~min}^{-1}$ ). Another 24 individual fibres were tested with change in the tensile rate to $0.25 \mathrm{~mm} / \mathrm{min}$ (strain rate $1.25 \mathrm{~min}^{-1}$ ) to examine the effect of loading rate on performance, as it was indicated in literature that might have an effect (Mukhopadhyay et al., 2008). A total of 60 stalk specimens were tested in a rate of $0.5 \mathrm{~mm} / \mathrm{min}$ ( 33 of shredded stalks and 27 cut ones); 19 specimens of shredded stems were tested at $0.2 \mathrm{~mm} / \mathrm{min}$. The modulus of elasticity was calculated as the slope of the linear part of the stress/strain graph for each individual specimen from its own elastic phase, which was ranging between $0.04-0.33$ of maximum strength in some specimens and $0.0-0.9$ in others.

\section{Outline of Data Analysis}

The effect of different contaminants, test rates, and preparation procedure of stalks was evaluated using the means and coefficients of variance. All the results were included in the calculations. 


\section{Results}

\section{Stalk and Fibre Geometry Studied Under SEM and Optical Microscope}

Straight stalk and fibre internode lengths were measured to be between 300 and $500 \mathrm{~mm}$ long. The cross-sectional area of the tested stalks samples ranged between 0.09 and 1.87 $\mathrm{mm}^{2}$, which is a massive variability mainly resulting from shredding processing. Fibre diameters varied from 190 to $350 \mu \mathrm{m}$, which is similar to the mean diameters of other natural fibres (Ali et al., 2013; Y. Li et al., 2000; Wolela, 2019). The connection node between fibres (Fig. 6) was found to have lengths between 5 and $6 \mathrm{~mm}$. This connection was noted as the weakest point of the fibre's length, and hence, it was removed before further testing.

\section{Morphology Studied Under SEM}

A cross-sectional view of a single sorghum fibre is shown in Fig. 7a. It consists of multiple microtubes, of diameters varying between 5 and $15 \mu \mathrm{m}$, that form a honeycomblike frame around three larger sized cells. The diameter of the larger cells ranged between 90 and $100 \mu \mathrm{m}$, while the smaller tubes were around $35 \mu \mathrm{m}$. Smaller pores (Fig. 7b) were observed on the side of the fibre and ranged between
0.7 and $2 \mu \mathrm{m}$. This porous structure can be contributing to the high level of water absorbency of the fibres.

\section{Tensile Strength}

\section{Fibres}

The tensile stress-strain response of a typical sorghum fibre is shown in Fig. 8. Tensile curves were found to be initially linear, propagating to a nonlinear phase after stress levels exceeded $30-50 \%$ of the maximum tensile strength. Failure at maximum stress was brittle. These results are consistent with literature (Kim \& Netravali, 2010), while the elongation in sorghum fibres was lower than other recorded natural fibres; this may suggest that these fibres are more brittle. Modulus of elasticity ranged from 0.9 to $33.6 \mathrm{GPa}$, and from 1.0 to $24.5 \mathrm{GPa}$ for fibres tested with 2.5 and $1.25 \mathrm{~min}^{-1}$, respectively. These values are lower than values reported for other natural fibres such as hemp which ranges between 14 and $70 \mathrm{MPa}$ (Kumar et al., 2019; Stevulova et al., 2014); this reflects them as being less stiff than other natural fibres.

The individual fibre tensile strengths varied from 24 to $167 \mathrm{MPa}$, with the mean strength and the coefficient of variance (CV) given in Table 1. The average values for both test rates were close, and both their CV were less than $100 \%$. The CV for the higher strain application rate was $20 \%$ higher
Fig. 6 SEM image for connection node between fibres
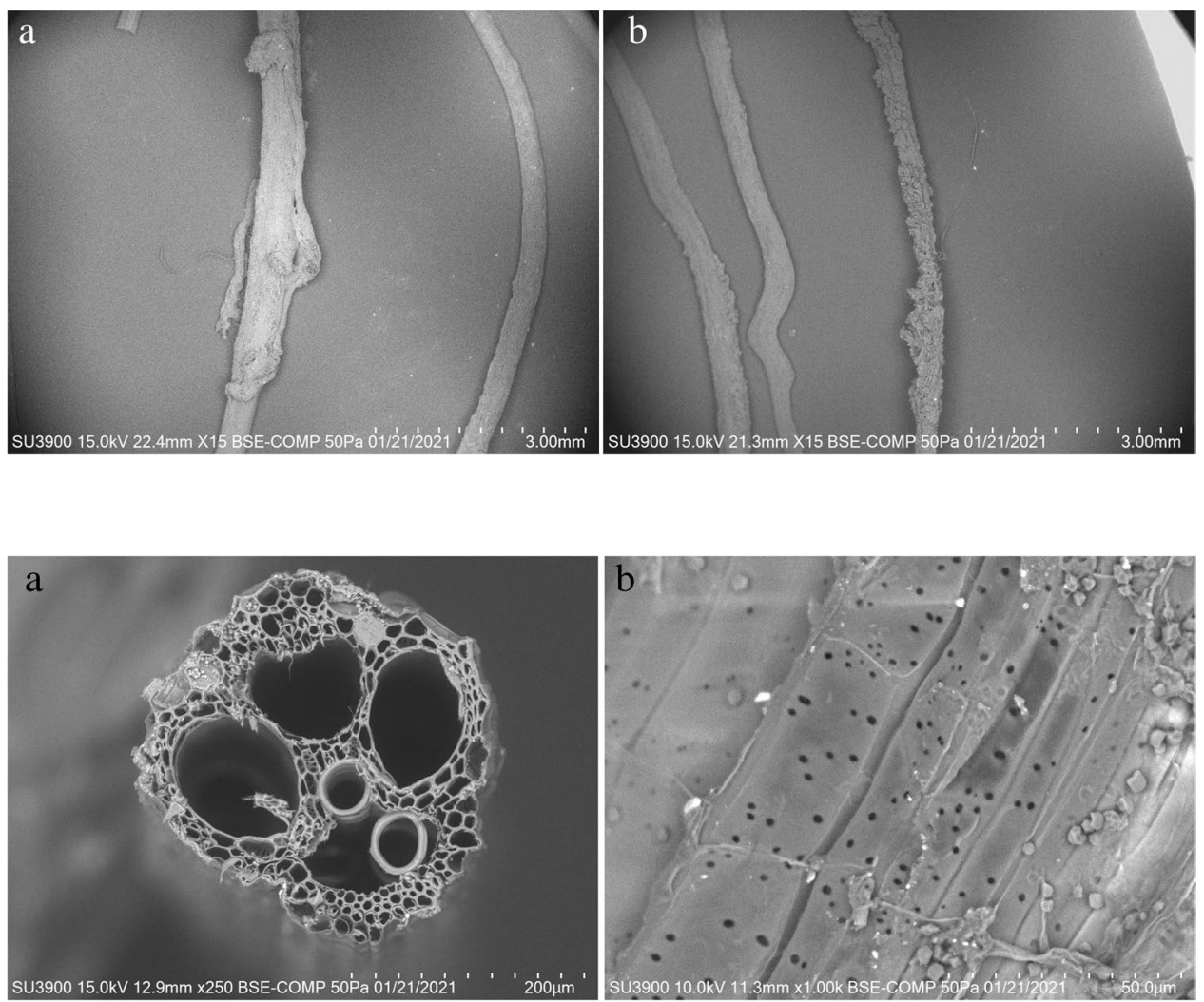

Fig. 7 SEM image of a single sorghum fibre. a Cross-section. b Side 


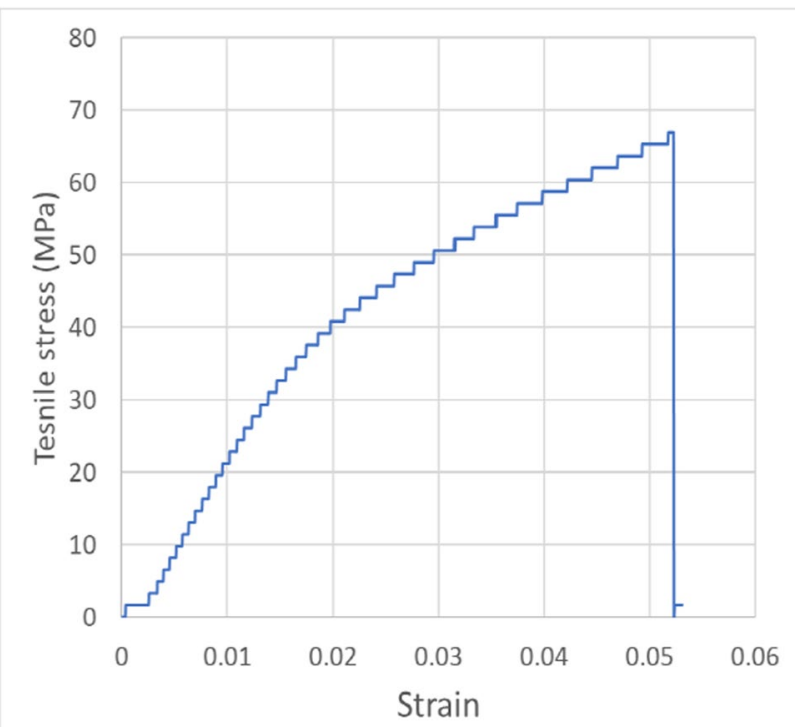

Fig. 8 Tensile test result of a single fibre

than for the lower strain application rate, but could be related to the larger sample size.

\section{Stalks}

The tensile stress-strain curve of a one cut stalk is shown in Fig. 9. Similar to fibre tests, the tensile curves were found to be initially linear then propagating to a nonlinear phase. In contrast, the stress-strain curves of the shredded samples, shown in Fig. 10, were found to be linear through to failure. Failure at maximum load was brittle. The response of six specimens is shown in Fig. 10, each couple of colours, light and dark (yellow, blue and green), represent samples with close tensile strength but with different tension rates. The modulus of elasticity for the cut specimen ranged from 2.5 to $19.8 \mathrm{GPa}$, while shredded specimens varied from as low as 1.3 and 5.8 $\mathrm{GPa}$ to a maximum of 32 and $18 \mathrm{GPa}$, for the strain rates

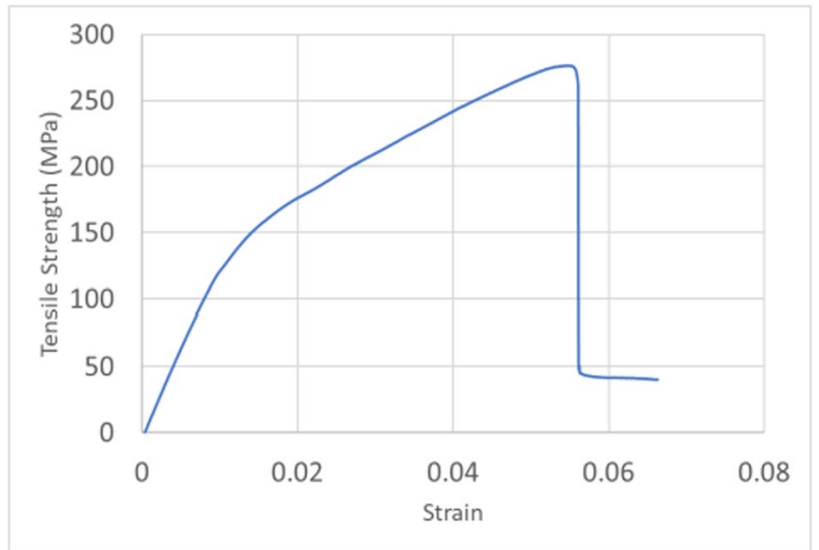

Fig. 9 Tensile test result of a single cut stalk

1.0 and $2.5 \mathrm{~min}^{-1}$, respectively. These values reflect a more consistent performance of cut samples compared to shredded ones.

The individual stalk tensile strength varied from a minimum of 10 and $28 \mathrm{MPa}$ up to 247 and $342 \mathrm{MPa}$ in cut and shredded samples, respectively. The averages and CVs are shown in Table 1. Figure 14 shows the dispersion of data collected from both cut and shredded samples. The averaged tensile strength for specimens tested with slower strain rate $\left(1.00 \mathrm{~min}^{-1}\right)$ was lower than the average for those tested with higher rate $\left(2.5 \mathrm{~min}^{-1}\right)$; nonetheless, the $\mathrm{CV}$ was higher for the former than the latter, reflecting more scattered data.

\section{Discussions}

\section{Morphology}

As was seen in Fig. 7, the fibre's cross-section was porous with more than $90 \%$ of the cross-sectional area being voids. This undoubtedly contributed to the high water absorbency of the fibres.
Table 1 Tensile strength parameters and results

\begin{tabular}{lllllll}
\hline Type & $\begin{array}{l}\text { Strain applica- } \\
\text { tion rate }\left(\mathrm{min}^{-1}\right)\end{array}$ & $\begin{array}{l}\text { No. of } \\
\text { specimens }\end{array}$ & Average $\mathrm{f}_{\mathrm{t}}(\mathrm{MPa})$ & $\mathrm{CV}-\mathrm{f}_{\mathrm{t}}(\%)$ & $\begin{array}{l}\text { Average } \\
\mathrm{E}(\mathrm{GPa})\end{array}$ & CV-E (\%) \\
\hline Fibres & 2.50 & 66 & 57.3 & 66.4 & 3.4 & 4.3 \\
& 1.25 & 24 & 49.0 & 47.3 & 3.5 & 4.6 \\
Cut stalks & 2.50 & 27 & 159.5 & 44.3 & 6.7 & 3.1 \\
Shredded stalks & 2.50 & 15 & 145.2 & 40.3 & 10.2 & 3.0 \\
& 1.00 & 19 & 91.5 & 74.1 & 7.0 & 6.9 \\
\hline
\end{tabular}

$f t$ tensile strength, $C V$ coefficient of variation, $E$ modulus of elasticity. 
Fig. 10 Tensile test result of six samples of shredded stalk

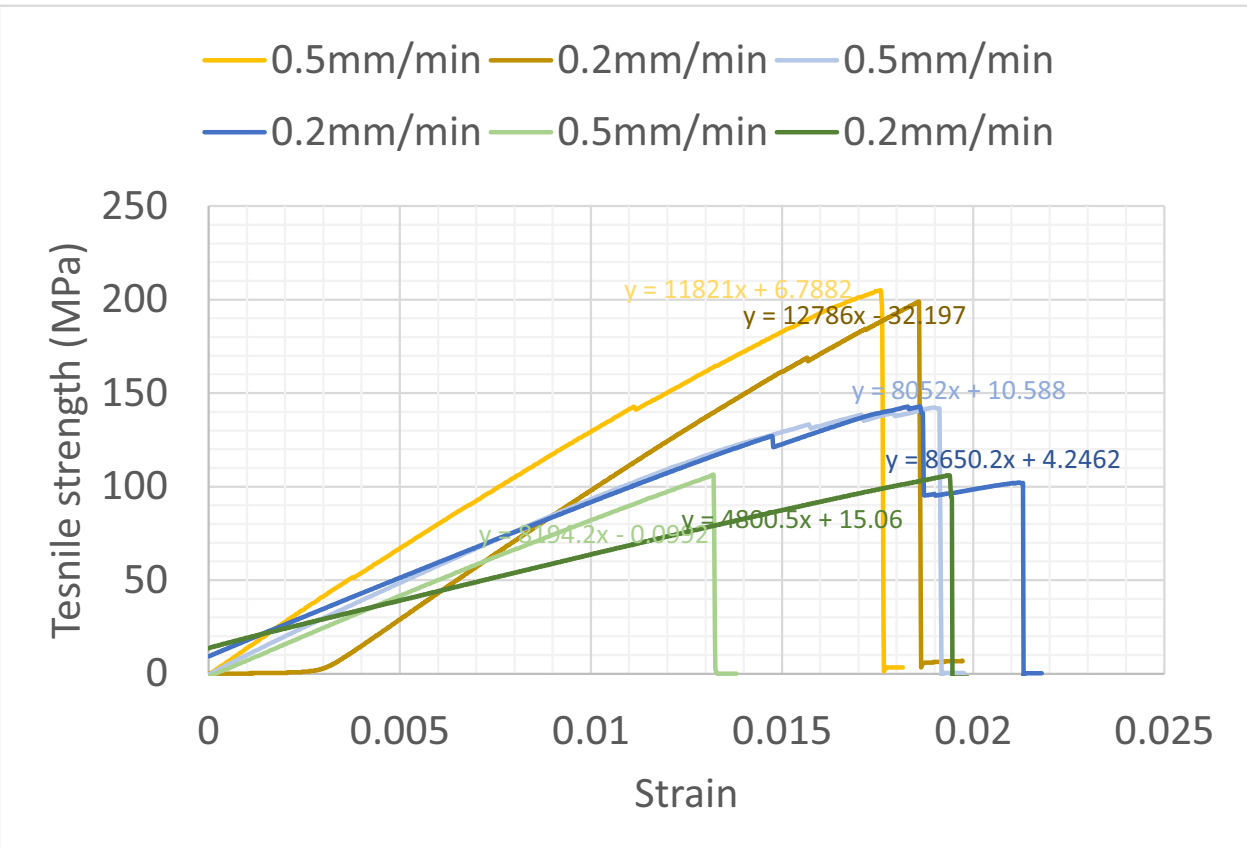

The microstructure of the fibres and stalks were studied with the use of MIP. The pore diameter that connects the larger pores is defined as the critical pore diameter, and indicates the connectivity of the specimen's pores and, consequently, how far liquid water will travel after intruding the specimen (Zhu et al., 2019). In MIP, testing a "critical pore diameter" is defined as the pore size corresponding to the highest peak in the $\mathrm{dV} / \mathrm{d} \log \mathrm{D}$ graph, indicating that the critical size of pores governing the specimen A "threshold diameter" is defined as the size beyond which the intruded volume increases significantly (Siddique, 2008); the threshold diameter provides a measure of how difficult it will be for water to penetrate in the specimen and consequently the specimen's permeability (Diamond et al., 2007). To minimise the effect of change in test parameters on test results (Beaudoin \& Marchand, 2001), all specimens of fibres and stalks were subjected to the same pre-treatment comprising storage in a $50{ }^{\circ} \mathrm{C}$ oven for a minimum of $48 \mathrm{~h}$ before testing. MIP testing on the sorghum fibre samples (Fig. 11a) showed that both the threshold diameter and the critical pore size are close to $40 \mu \mathrm{m}$. For the shredded stalks (Fig. 11b), pore sizes were distributed across 0.003 to $100 \mu \mathrm{m}$, with a critical pore size of an average $19 \mu \mathrm{m}$. Shredded samples did not show a specific threshold diameter.

One of the cut stalks indicated a rather different behaviour under mercury intrusion, as presented in Fig. 11c. This specimen was discarded from the average calculations. Cut specimens presented three main peaks in the $\mathrm{dV} / \mathrm{d} \log \mathrm{D} \log$, corresponding to three critical diameters, namely $0.065 \mu \mathrm{m}, 0.7 \mu \mathrm{m}$, and $30 \mu \mathrm{m}$. These pore values correlate to the very high level of water absorption (180\%) of the sorghum stalks. During MIP tests, most of the pores were filled with relatively low pressures $(<20 \mathrm{MPa}$, where stabilised soil bricks are pressed with less than $4 \mathrm{MPa}$ (Adam, 2001)) as depicted in Fig. 12. Fibres showed more volume intrusion than stalks as can be seen in Fig. 12, while shredding and cutting the stalks did not have a constant effect on their debility to intrude mercury. The higher volume intruded in fibres can be due to their extremely porous structure shown in Fig. 7, while the stalks retain the dermal tissue which minimise its porosity.

All of these results are evidence of the high porosity of the fibres and stalks, and hence, to their high water absorption. This should be considered when adding sorghum fibres and stalks to the soil bricks or cement blocks.

\section{Tensile Strength}

\section{Fibres}

Despite the low and variable tensile strength of the sorghum fibres under study, in comparison to other fibres (Akubueze et al., 2019; Kumar et al., 2019), they have potential as reinforcement in bricks in lowcost housing. Fibres with much lower tensile strength ( $<16 \mathrm{MPa}$ ) have been used successfully in unfired clay bricks (Salih et al., 2020a). Furthermore, the 


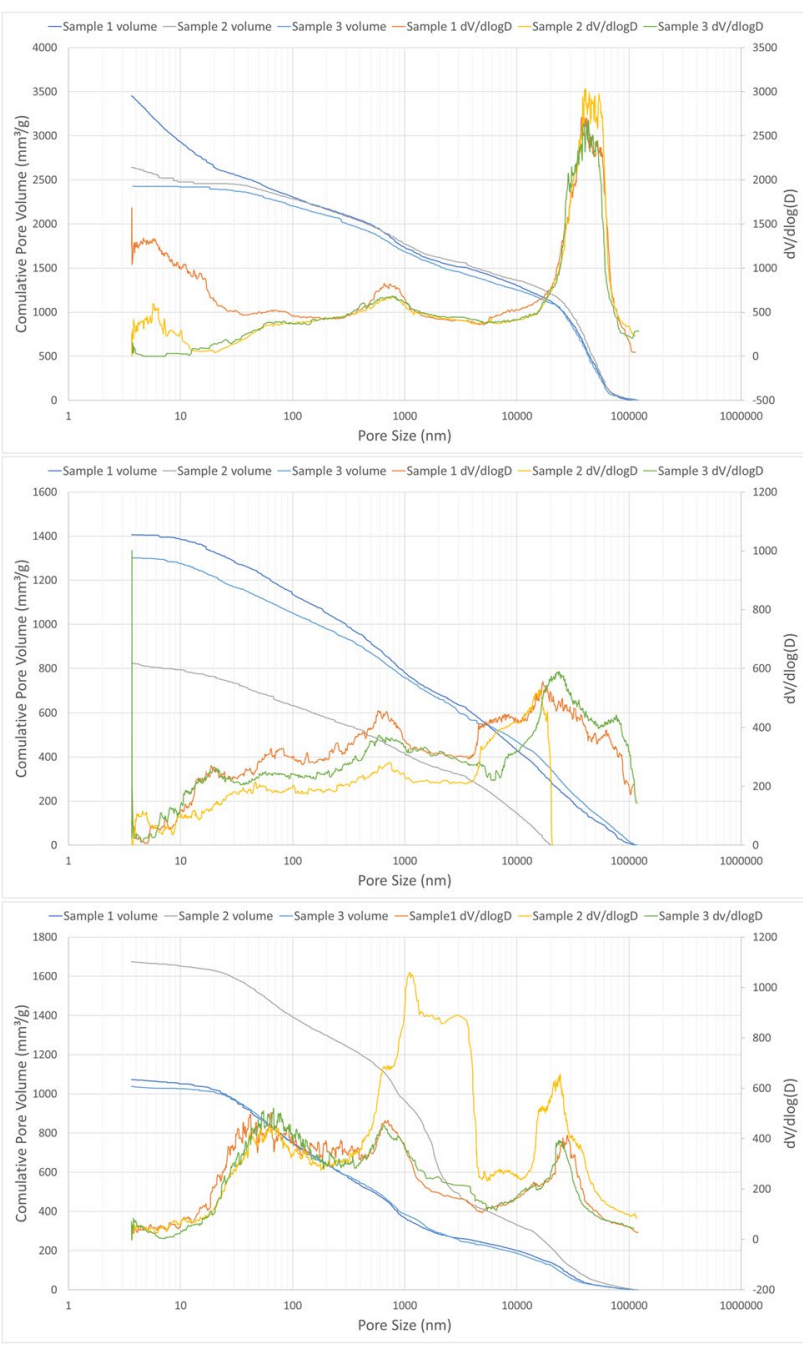

Fig. 11 MIP results for fibre (top), shredded stalks (middle), and cut stalks (bottom)

cross-sectional area of the fibres is overvalued for simplicity purposes and lack of equipment to determine the actual net area. This reflects a much higher strength than recorded here.

Treating the fibres with sodium hydroxide has previously been used to improve properties of natural fibres (Kim \& Netravali, 2010; Meon et al., 2012). As part of on-going research, further tests are planned to understand the sorghum fibre behaviour in a soil clay matrix.

When observed under both optical microscope and SEM, some of the sorghum fibres were found to be partially or completely covered with wax or black spots, the later indicative of mould growth. The effect of these contaminants on the tensile strength of fibres was explored further; fibre tensile strength results were found to be similar to the clean fibres (Fig. 13a).

The effect of strain rate in testing, varying between 1.25 and $2.5 \mathrm{~min}^{-1}$, on fibre tensile strength was also investigated (Fig. 13b). There was little direct correlation between strain rate and tensile strengths, although the samples tested with $1.25 \mathrm{~min}^{-1}$ were less scattered compared to the higher rate.

\section{Stalks}

From Figs. 9 and 10, while both kinds of stalks failed in a brittle manner, shredded samples showed linear behaviour while cut samples demonstrated nonlinear behaviour in certain stages as explained earlier. This can be rationalised by the shredder breaking down the fibres constructing the stalk, while the manually cut stalks maintained their fibre integrity, hence underwent individual fibre failure at a time.

The effect of the test rate was found to not highly affect the behaviour of the shredded stalks undergoing tensile strength (Fig. 10), although a less scattered data can be argued with the lower CV value of the samples tested with higher test rate. While all the samples' behaviour was highly variable, the modulus of elasticity results indicated a more consistent behaviour in comparison to the shredded ones.

From Fig. 14 and Table 1, most of the specimen's results are clustering around an average strength of $130 \mathrm{MPa}$, which is lower than those recorded by Bakeer et al. (2013) for sorghum stalks; this difference can be attributed to the variation in number of specimens between both studies, as well as the difference in specimen's preparation.

\section{Conclusions}

In this study, sorghum stalks and fibres were tested to understand their morphology and to assess their viability in earth bricks and cement-based construction blocks for low-cost housing. The use of sorghum stalks waste can enhance the quality of housing in low-income countries in line with the vernacular structures in the region in which stalks are used to stabilise mud structures. This study is a step forward into increasing the durability of those structures with the least possible cost and impact on the environment. This study is a part of ongoing research to evaluate the possibility of using agricultural waste from Sudan in construction materials. The limited 
Fig. 12 Pore size vs pressure for fibre samples

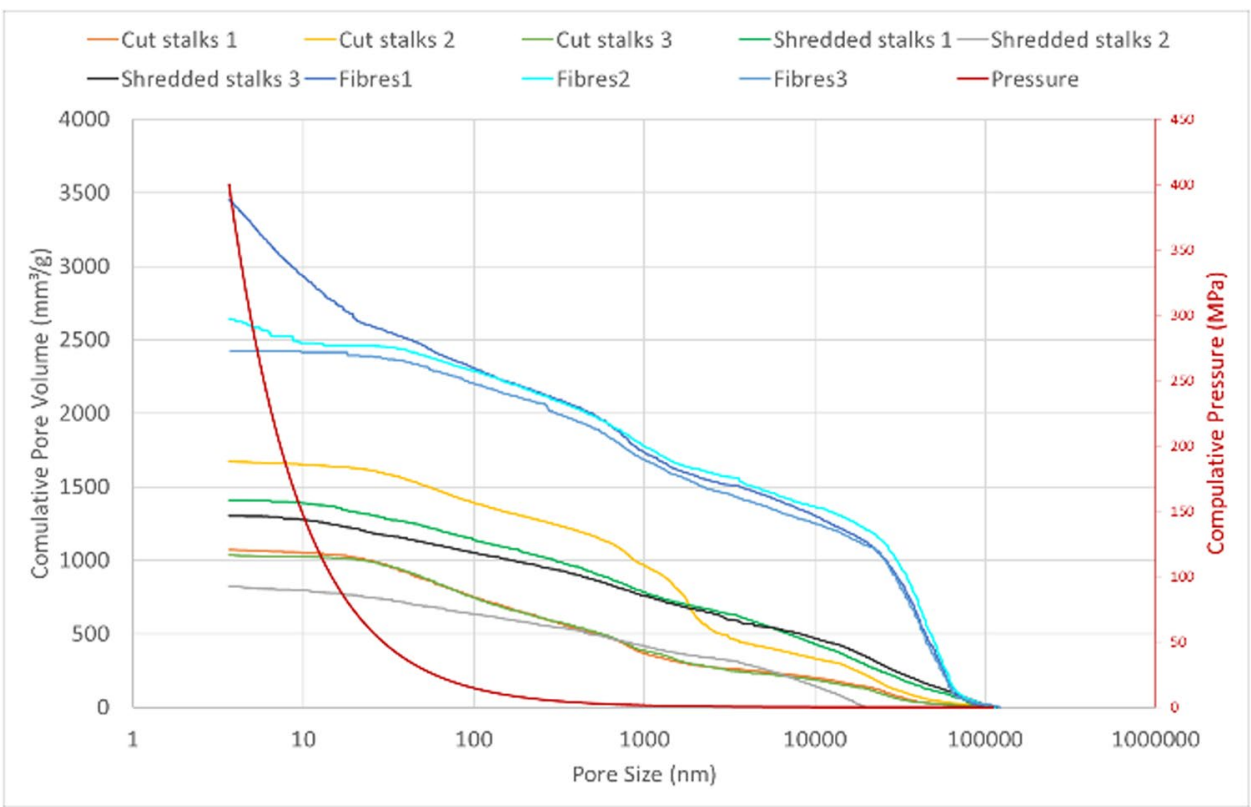

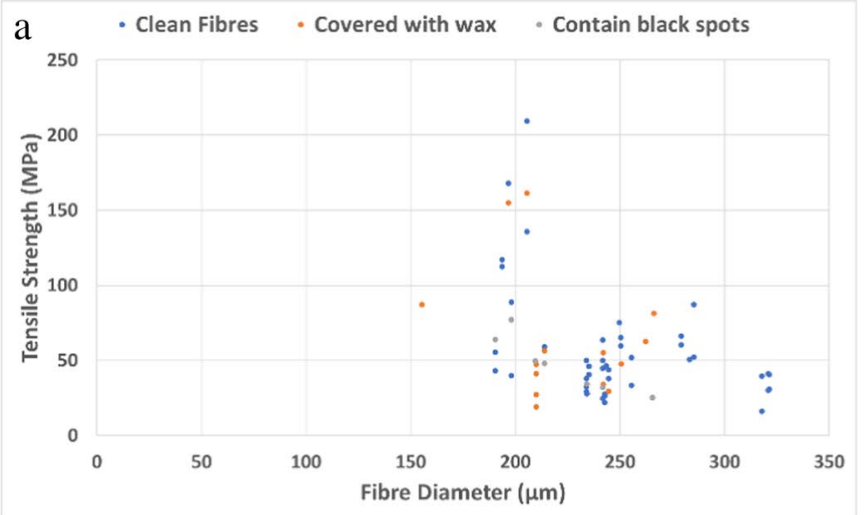

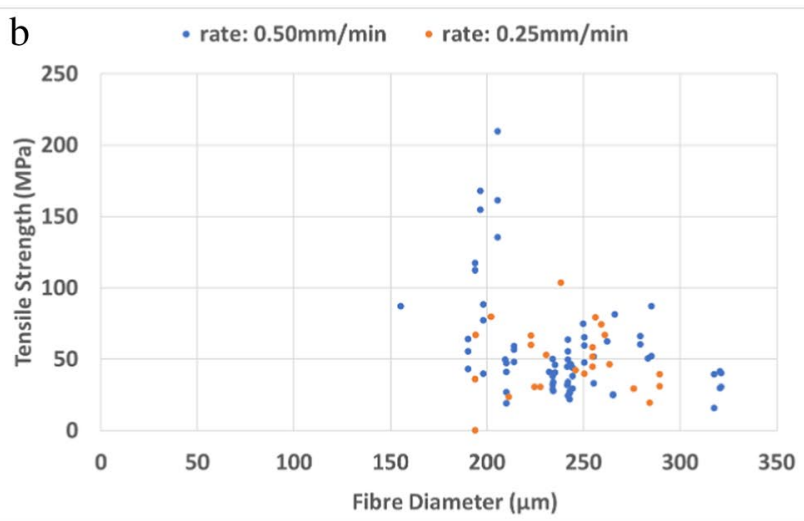

Fig. 13 Fibre diametae $r$ vs Tensile strength a) effect of contaminants on fibre surfaceb, b) effect of test rate

time of the study did not help in applying more tests such as pull-out test and chemical characterisation, and the nature of importing crops from a different country limited the sample size giving indicative, but not conclusive, results on the viability of sorghum fibres and stalks; also, it resulted in working with one type of sorghum from Sudan. From conducted tests, the following specific conclusions and recommendations can be drawn:

1- Sorghum stalks and fibres demonstrate variable mechanical properties, complicating their characterisation as individual fibres or within a matrix.
2- For low-cost housing construction materials, the tested stalks and fibres showed sufficient strength for use in unfired clay bricks.

3- The high porosity of fibres and stalks needs to be managed before further use in soil or a concrete matrix.

4- Further research to investigate performance of the fibres and stalks within a soil or concrete matrix is needed, and the effect of natural contaminants, such as wax, on the bond should be noted.

5- Further research to investigate the effect of various species of sorghum and differences in their strength among other properties is needed. 
Fig. 14 Tensile stress vs area for stalks

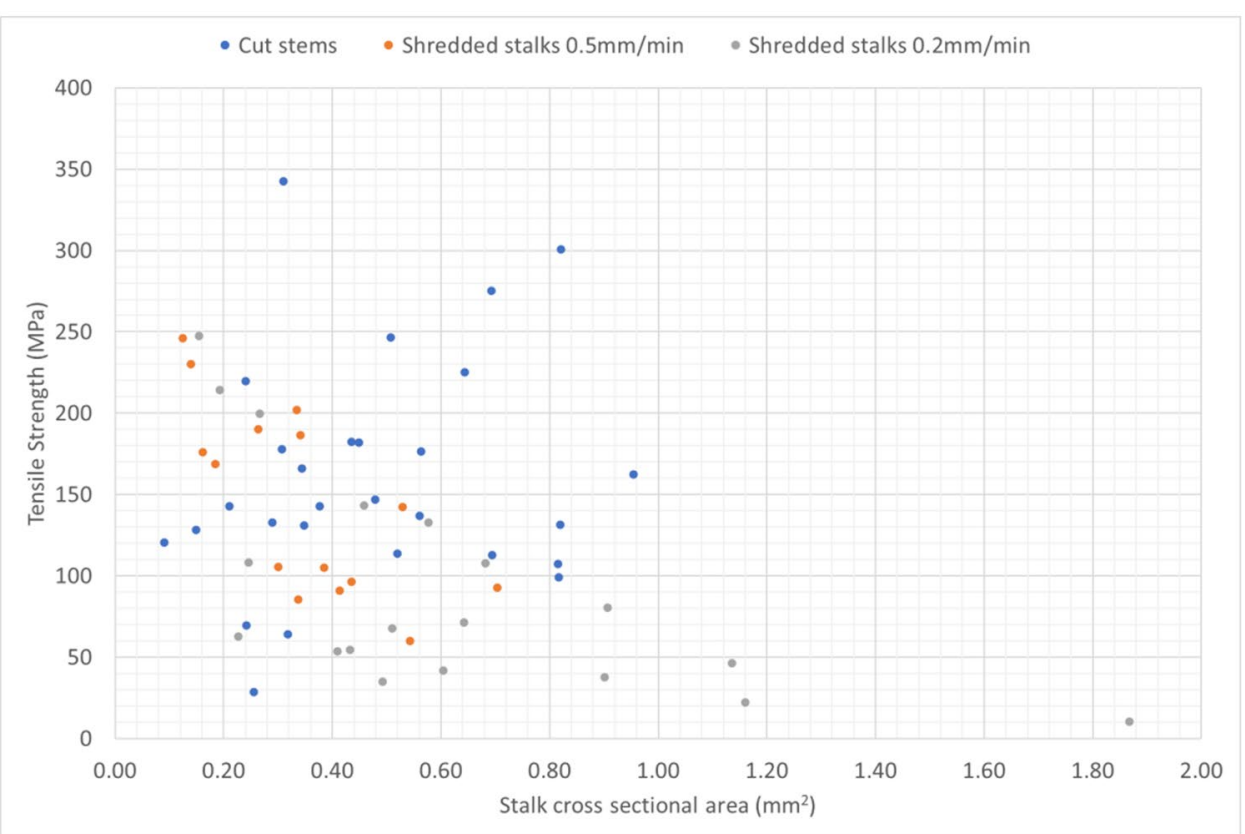

Author Contribution T.A. carried out the experiments, data analysis, and led drafting of the paper. P.W., K.P., and S.A. supervised the experimental work and data analysis. All authors contributed to the final manuscript drafting.

Funding This research is a part of $\mathrm{PhD}$ research conducted at the University of Bath, UK, and funded by Schulmberger's Faculty for the Future (fftf) fellowship for women in STEM.

Data Availability The datasets generated and analysed during the current study are not publicly available due to it being a part of an ongoing $\mathrm{PhD}$ research, but are available from the corresponding author on reasonable request.

\section{Declarations}

Conflict of Interest The authors declare no competing interests.

Open Access This article is licensed under a Creative Commons Attribution 4.0 International License, which permits use, sharing, adaptation, distribution and reproduction in any medium or format, as long as you give appropriate credit to the original author(s) and the source, provide a link to the Creative Commons licence, and indicate if changes were made. The images or other third party material in this article are included in the article's Creative Commons licence, unless indicated otherwise in a credit line to the material. If material is not included in the article's Creative Commons licence and your intended use is not permitted by statutory regulation or exceeds the permitted use, you will need to obtain permission directly from the copyright holder. To view a copy of this licence, visit http://creativecommons.org/licenses/by/4.0/.

\section{References}

Adam, E. a. (2001). Compressed stabilized earth block manufacturing in Sudan - UNESCO - Technical Note No. 12. United Nations Educ. Sci. Cult. Organ., 101.
Akubueze EU, Ezeanyanaso CS, Muniru OS, Nwaeche FC, Tumbi MI, Igwe CC, Elemo GN (2019) Extraction and characterization of bast fibres from Roselle (Hibiscus sabdariffa) stem for industrial application. J Mater Sci Res Rev 2(4):1-7. https://doi.org/10. 9734/JMSRR/2019/45087

Alamin, H. A. (2007). The Sorghum (in Arabic). Sudan Trade Point.

Ali M, Li X, Chouw N (2013) Experimental investigations on bond strength between coconut fibre and concrete. Mater Des 44:596605. https://doi.org/10.1016/j.matdes.2012.08.038

Bakeer B, Taha I, El-Mously H, Shehata SA (2013) On the characterisation of structure and properties of sorghum stalks. Ain Shams Eng J 4:265-271. https://doi.org/10.1016/j.asej.2012.08.001

Beaudoin, J. J., \& Marchand, J. (2001). Pore structure. In V. S. Ramachandran \& J. J. Beaudoin (Eds.), HANDBOOK OF ANALYTICAL TECHNIQUES IN CONCRETE SCIENCE AND TECHNOLOGY: Principles, Techniques, and Applications (pp. 528628). William Andrew Publishing/Noyes Publications. https://doi. org/10.1016/B978-0-8155-1437-4.50017-5

Chen X (2020) Variations in patterns of internode and branch lengths for several bamboo species. Plant Biosyst - an Int J Deal with All Asp Plant Biol. https://doi.org/10.1080/11263504.2020.1829729

Cigasova J, Stevulova N, Junak J (2013) Properties monitoring of fibrous composites based on hemp hurds with different mean particle size. Pollack Period 8(2):41-46. https://doi.org/10.1556/ Pollack.8.2013.2.5

Diamond, S., Brooks, J. J., Bensted, J., Page, C. L., Nurnberger, U., Sawade, G., Thomas, M. D. A., Folliard, K. J., Richardson, M., Purnell, P., \& Short, N. R. (2007). Durability of concrete and cement composites (C. L. Page \& M. M. Page (eds.)). Woodhead Publishing Limited.

Duval A, Bourmaud A, Augier L, Baley C (2011) Influence of the sampling area of the stem on the mechanical properties of hemp fibers. Mater Lett 65(4):797-800. https://doi.org/10.1016/j.matlet.2010.11.053

Eliche-Quesada D, Martínez-García C, Martínez-Cartas ML, CotesPalomino MT, Pérez-Villarejo L, Cruz-Pérez N, Corpas-Iglesias FA (2011) The use of different forms of waste in the manufacture of ceramic bricks. Appl Clay Sci 52(3):270-276. https://doi.org/ 10.1016/j.clay.2011.03.003

FAO. (2019). World Food and Agriculture - Statistical Pocketbook 2019. In World Food and Agriculture - Statistical Pocketbook 
2019. Food and Agriculture Organization of the United Nations. https://doi.org/10.4060/ca1796en

Farhan, K. Z., Johari, M. A. M., \& Demirboğa, R. (2021). Impact of fiber reinforcements on properties of geopolymer composites: a review. J. Build. Eng., 44. https://doi.org/10.1016/j.jobe.2021. 102628

Ismojo, Novovic, A., Lazwardi, D. R., Zulfia, A., \& Chalid, M. (2019). Microfibrillated cellulose (MFC) isolation based on stalk sweet sorghum through alkalinization-bleaching treatment: effect of soaking temperature. IOP Conf. Ser. Mater. Sci. Eng., 509(1). https://doi.org/10.1088/1757-899X/509/1/012079

Kim JT, Netravali AN (2010) Mercerization of sisal fibers: effect of tension on mechanical properties of sisal fiber and fiber-reinforced composites. Compos Part A Appl Sci Manuf 41(9):1245-1252. https://doi.org/10.1016/j.compositesa.2010.05.007

Kumar R, Ul Haq MI, Raina A, Anand A (2019) Industrial applications of natural fibre-reinforced polymer composites-challenges and opportunities. Int J Sustain Eng 12(3):212-220. https://doi.org/ 10.1080/19397038.2018.1538267

Li Q, Ibrahim L, Zhou W, Zhang M, Yuan Z (2021) Treatment methods for plant fibers for use as reinforcement in cement-based materials. Cellulose 28(9):5257-5268. https://doi.org/10.1007/ s10570-021-03903-w

Li Y, Mai Y, Ye L (2000) Sisal fibre and its composites : a review of recent developments. Compos Sci Technol 60(2000):2037-2055

Meon, M. S., Othman, M. F., Husain, H., Remeli, M. F., \& Syawal, M. S. M. (2012). Improving tensile properties of kenaf fibers treated with sodium hydroxide. Procedia Eng., 41(Iris), 1587-1592. https://doi.org/10.1016/j.proeng.2012.07.354

Merta I, Tschegg EK (2013) Fracture energy of natural fibre reinforced concrete. Constr Build Mater 40:991-997. https://doi.org/10. 1016/j.conbuildmat.2012.11.060

Millogo Y, Morel JC, Aubert JE, Ghavami K (2014) Experimental analysis of Pressed Adobe Blocks reinforced with Hibiscus cannabinus fibers. Constr Build Mater 52:71-78. https://doi.org/10. 1016/j.conbuildmat.2013.10.094

Mirata M, Emtairah T (2005) Industrial symbiosis networks and the contribution to environmental innovation: the case of the Landskrona industrial symbiosis programme. J Clean Prod 13(1011):993-1002. https://doi.org/10.1016/j.jclepro.2004.12.010

Mukhopadhyay S, Fangueiro R, Arpaç Y, Şentürk Ü (2008) Banana fibers - variability and fracture behaviour. J Eng Fiber Fabr 3(2):155892500800300. https://doi.org/10.1177/1558925008 00300207

Onuaguluchi O, Banthia N (2016) Plant-based natural fibre reinforced cement composites: a review. Cem Concr Compos 68:96-108. https://doi.org/10.1016/j.cemconcomp.2016.02.014

Perrier, L., Rouan, L., Jaffuel, S., Clément-Vidal, A., Roques, S., Soutiras, A., Baptiste, C., Bastianelli, D., Fabre, D., Dubois, C., Pot, D., \& Luquet, D. (2017). Plasticity of sorghum stem biomass accumulation in response to water deficit: a multiscale analysis from internode tissue to plant level. Front. Plant Sci., 8(September). https://doi.org/10.3389/fpls.2017.01516

Salih MM, Osofero AI, Imbabi MS (2020) Constitutive models for fibre reinforced soil bricks. Constr Build Mater 240:1-21. https://doi. org/10.1016/j.conbuildmat.2019.117806
Salih, M. M., Osofero, A. I., \& Imbabi, M. S. (2020b). Critical review of recent development in fiber reinforced adobe bricks for sustainable construction. Front. Struct. Civ. Eng. https://doi.org/10.1007/ s11709-020-0630-7

Shooshtarian S, Caldera S, Maqsood T, Ryley T (2020) Using recycled construction and demolition waste products: a review of stakeholders' perceptions, decisions, and motivations. Recycling 5(4):31. https://doi.org/10.3390/recycling5040031

Shooshtarian S, Hosseini MR (2021) Use of recycled construction and demolition waste in the landscape industry. Int $\mathbf{J}$ for Soil Eros 11(2):37-44

Siddique R (2008) Waste materials and by-products in concrete. Springer

Stevulova N, Cigasova J, Estokova A, Terpakova E, Geffert A, Kacik F, Singovszka E, Holub M (2014) Properties characterization of chemically modified hemp hurds. Materials (basel) 7:8131-8150. https://doi.org/10.3390/ma7128131

Stevulova, N., \& Junak, J. (2012). Study of strength characteristics of hemp composite. 4th Int. Conf. Eng. Waste Biomass Valoris., September, 1539-1544.

Sung, K. (2015). A review on upcycling: current body of literature, knowledge gaps and a way forward. Int. Conf. Environ. Cult. Econ. Soc. Sustain. Venice, 17(4), 28-40.

Sung K, Cooper T, Kettley S (2019) Factors influencing upcycling for UK makers. Sustain 11(3):1-26. https://doi.org/10.3390/su110 30870

Surpam T, Pardeshi I, HN, R. (2019) Engineering properties of Sorghum. Int J Chem Stud 7(5):108-110

Symington MC, Banks WM, West OD, Pethrick RA (2009) Tensile testing of cellulose based natural fibers for structural composite applications. J Compos Mater 43(9):1083-1108. https://doi.org/ 10.1177/0021998308097740

Taallah B, Guettala A, Guettala S, Kriker A (2014) Mechanical properties and hygroscopicity behavior of compressed earth block filled by date palm fibers. Constr Build Mater 59:161-168. https://doi. org/10.1016/j.conbuildmat.2014.02.058

The World Bank. (2021). World Bank Country and Lending Groups Country Classification. https://datahelpdesk.worldbank.org/knowl edgebase/articles/906519

Thomas BS (2018) Green concrete partially comprised of rice husk ash as a supplementary cementitious material - a comprehensive review. Renew Sustain Energy Rev 82:3913-3923. https://doi.org/ 10.1016/j.rser.2017.10.081

UN. (2015). World Population Prospects The 2015 Revision. In Department of Economic and Social Affairs (DESA).

Wolela AD (2019) Extraction and characterization of natural cellulose fibers from Sanseveria trifasciata plant. Trends Text Eng Fash Technol 5(2):630-634. https://doi.org/10.31031/TTEFT.2019.05. 000609. Nowadays

Zhu J, Zhang R, Zhang Y, He F (2019) The fractal characteristics of pore size distribution in cement-based materials and its effect on gas permeability. Sci Rep 9(1):1-12. https://doi.org/10.1038/ s41598-019-53828-5

Publisher's Note Springer Nature remains neutral with regard to jurisdictional claims in published maps and institutional affiliations. 